\title{
A MOLECULAR-ORBITAL MODEL FOR AMORPHOUS GROUP IV SEMICONDUCTORS
}

\author{
M.A. GRADO-CAFFARO* and M. GRADO-CAFFARO \\ Member of the Academy of Sciences of New York; C. Julio Palacios, 11, 9-B, \\ 28029-Madrid, Spain
}

(Received 19 February 1996; In final form 17 June 1996)

\begin{abstract}
A theoretical model based on standard molecular-orbital theory and extended Hückel approach is proposed. This model is valid for amorphous group IV semiconductors and represents a substantial improvement of the state of the art.
\end{abstract}

\section{INTRODUCTION}

It is well-known that cluster approach, extended Hückel theory, and standard molecular-orbital theory may be employed to analyze the fundamental aspects of electronic density of states and infrared spectra in amorphous group IV semiconductors [1][2]. On the other hand, to apply standard molecular-orbital theory, a conventional perturbation method must be used. The aim of this paper is to achieve a main formula as a summary of a quantum-mechanical development that includes cluster approach, extended Hückel theory, and conventional molecular-orbital theory as basic ingredients.

\footnotetext{
*Corresponding author.
} 


\section{THEORY}

First, let us examine the following expression [3]:

$$
\mathrm{g}(\mathrm{x}, \mathrm{y}, \mathrm{z}, \mathrm{E})=\sum_{\mathrm{n}}\left|\psi_{\mathrm{n}}(\mathrm{x}, \mathrm{y}, \mathrm{z})\right|^{2} \delta\left(\mathrm{E}-\mathrm{E}_{\mathrm{n}}\right)
$$

where $g$ denotes local density of states in a cluster, $\psi_{n}$ are the eigenfunctions associated with EHT (Extended Hückel Theory), $\delta$ is the Dirac function, $E$ is energy, $E_{n}$ denotes energy eigenvalues, and $x, y, z$ are the cartesian coordinates.

Hence, the total density of states of the cluster is given by:

$$
g(E)=\iiint_{D} g(x, y, z, E) d x d y d z
$$

where $\mathrm{D}$ is the volume of the cluster.

The set of discrete eigenvalues $\mathrm{E}_{\mathrm{n}}$ arises from a consideration of clusters isolated in vacuum. A cluster approach can be realized by using a number of methods, but these methods must satisfy some conditions; one of these conditions is that finite clusters of the same size can take up distinct configurations, and it is important to have a configuration average of these clusters [4].

Now, we consider the basic equations associated with EHT-MO (molecular orbital), namely [3][5]:

$$
\begin{gathered}
\sum_{j=1}^{N}\left(\hat{H}_{i j}-E_{1} S_{i j}\right) C_{1 j}=0 \\
\sum_{j=1}^{N}\left(\hat{H}_{i j}-E_{2} S_{i j}\right) C_{2 j}=0(i=1,2, \ldots, N)
\end{gathered}
$$

where $\hat{\mathrm{H}}_{\mathrm{ij}}$ denotes hamiltonian, $\mathrm{i}$ and $\mathrm{j}$ stand for the atomic orbitals, $\mathrm{S}_{\mathrm{ij}}$ are the overlap integrals between the atomic orbitals, and $\mathrm{C}_{1 \mathrm{j}}, \mathrm{C}_{2 \mathrm{j}}$ are the molecular orbitals coefficients. Moreover, $\mathrm{E}_{1}$ and $\mathrm{E}_{2}$ represent the energies associated with molecular orbitals.

Let us now consider amorphous $\mathrm{Si}$. By considering $\mathrm{s}$ orbitals and $\mathrm{p}$ orbitals, we have the following molecular orbitals: 


$$
\begin{aligned}
& \phi_{1}=\psi_{\mathrm{s}}-\alpha \psi_{\mathrm{p}} \\
& \phi_{2}=\psi_{\mathrm{p}}+\beta \psi_{\mathrm{s}}
\end{aligned}
$$

where $\psi_{\mathrm{s}}$ is s orbital and $\psi_{\mathrm{p}}$ is $\mathrm{p}$ orbital. Moreover, $\alpha$ and $\beta$ are small admixture coefficients. Note that $\phi_{1}$ and $\phi_{2}$ are the antibonding and bonding orbitals, respectively. In this context, we shall use standard perturbation theory [6] by means of the following expression:

$$
\phi_{1}=\psi_{\mathrm{s}}^{(\mathrm{o})}+\psi_{\mathrm{s}}^{(\mathrm{k})}=\psi_{\mathrm{s}}+\frac{\mathrm{a}_{\mathrm{sp}}}{\mathrm{E}_{\mathrm{s}}-\mathrm{E}_{\mathrm{p}}} \psi_{\mathrm{p}}
$$

with $\psi_{s}^{(k)}$ the kth perturbed term and $\mathrm{a}_{\mathrm{sp}}=\left\langle\psi_{\mathrm{s}}\left|\hat{\mathrm{H}}_{\mathrm{sp}}\right| \psi_{\mathrm{p}}\right\rangle, \hat{\mathrm{H}}_{\mathrm{sp}}$ being the corresponding hamiltonian of perturbation.

From (5) and (7) we get:

$$
\alpha=-\frac{a_{s p}}{E_{s}-E_{p}}
$$

Similarly, it is deduced:

$$
\beta=\alpha=-\frac{\mathrm{a}_{\mathrm{sp}}}{\mathrm{E}_{\mathrm{s}}-\mathrm{E}_{\mathrm{p}}}
$$

Applying second-order perturbation theory, it is easy to compute the energetic shift of the molecular orbital $\phi_{1}$, namely:

$$
\Delta \mathrm{E}=\mathrm{a}_{\mathrm{sp}}^{2}\left(\mathrm{E}_{\mathrm{s}}-\mathrm{E}_{\mathrm{p}}\right)^{-1}=\alpha^{2}\left(\mathrm{E}_{\mathrm{s}}-\mathrm{E}_{\mathrm{p}}\right)
$$

by considering eq. (8).

Now we have: $\mathrm{E}_{1} \equiv \mathrm{E}_{\mathrm{A}}, \mathrm{E}_{2} \equiv \mathrm{E}_{\mathrm{B}}, \mathrm{C}_{1 \mathrm{j}} \equiv \mathrm{C}_{\mathrm{Aj}}, \mathrm{C}_{2 \mathrm{j}} \equiv \mathrm{C}_{\mathrm{Bj}}, \mathrm{N}=2 ; 1 \equiv$ $\mathrm{s}$, and $2 \equiv \mathrm{p}$ for atomic orbitals with:

$$
\mathrm{S}_{\mathrm{ij}}=\left\langle\psi_{\mathrm{i}}\left|\hat{\mathrm{H}}_{\mathrm{ij}}\right| \psi_{\mathrm{j}}\right\rangle(\mathrm{i}, \mathrm{j}=1,2)
$$

Now from (3), (4) and (10) we obtain: 


$$
\begin{gathered}
\sum_{j=1}^{2}\left\{\hat{H}_{\mathrm{ij}}\left(\mathrm{C}_{\mathrm{Aj}}-\mathrm{C}_{\mathrm{Bj}}\right)+\mathrm{S}_{\mathrm{ij}}\left\{\left[\alpha^{2} \mathrm{C}_{\mathrm{Aj}}+\left(1+\alpha^{2}\right) \mathrm{C}_{\mathrm{Bj}}\right] \mathrm{E}_{\mathrm{p}}-\right.\right. \\
\left.\left.\left[\left(1+\alpha^{2}\right) \mathrm{C}_{\mathrm{Aj}}+\alpha^{2} \mathrm{C}_{\mathrm{Bj}}\right] \mathrm{E}_{\mathrm{s}}\right\}\right\}=0
\end{gathered}
$$

since $\mathrm{E}_{\mathrm{A}}=\mathrm{E}_{\mathrm{S}}+\Delta \mathrm{E}$ and $\mathrm{E}_{\mathrm{B}}=\mathrm{E}_{\mathrm{p}}-\Delta \mathrm{E}$.

\section{CONCLUDING REMARKS}

Formulae (10) and (11) are very important since these expressions allow us to perform numerical computations to obtain energy values for amorphous Si. Consider an amorphous Si molecule and examine Si-Si bond [7]; our formulation is relevant for this examination.

\section{References}

[1] M.A. Grado, M. Grado. Physics Letters A, 169, No. 5, 399-401 (1992).

[2] R. Alben, P. Steinhardt, D. Weaire. AIP Conf. Proc., No. 20, 213-217 (1974).

[3] B.Y. Tong. AIP Conf. Proc., No. 20, 145-149 (1974).

[4] W.H. Butler, W. Kohn. J. of Res. NBS 74 A, 443 (1970).

[5] C.C.J. Roothaan. Reviews of Modern Phys. 23, 69 (1951).

[6] J. Owen. J.M.H. Thornley. Rep. Prog. Phys. 29, 675 (1966).

[7] Y. Hamakawa, ed., Amorphous semiconductor technologies and devices (North-Holland, Amsterdam, 1986). 

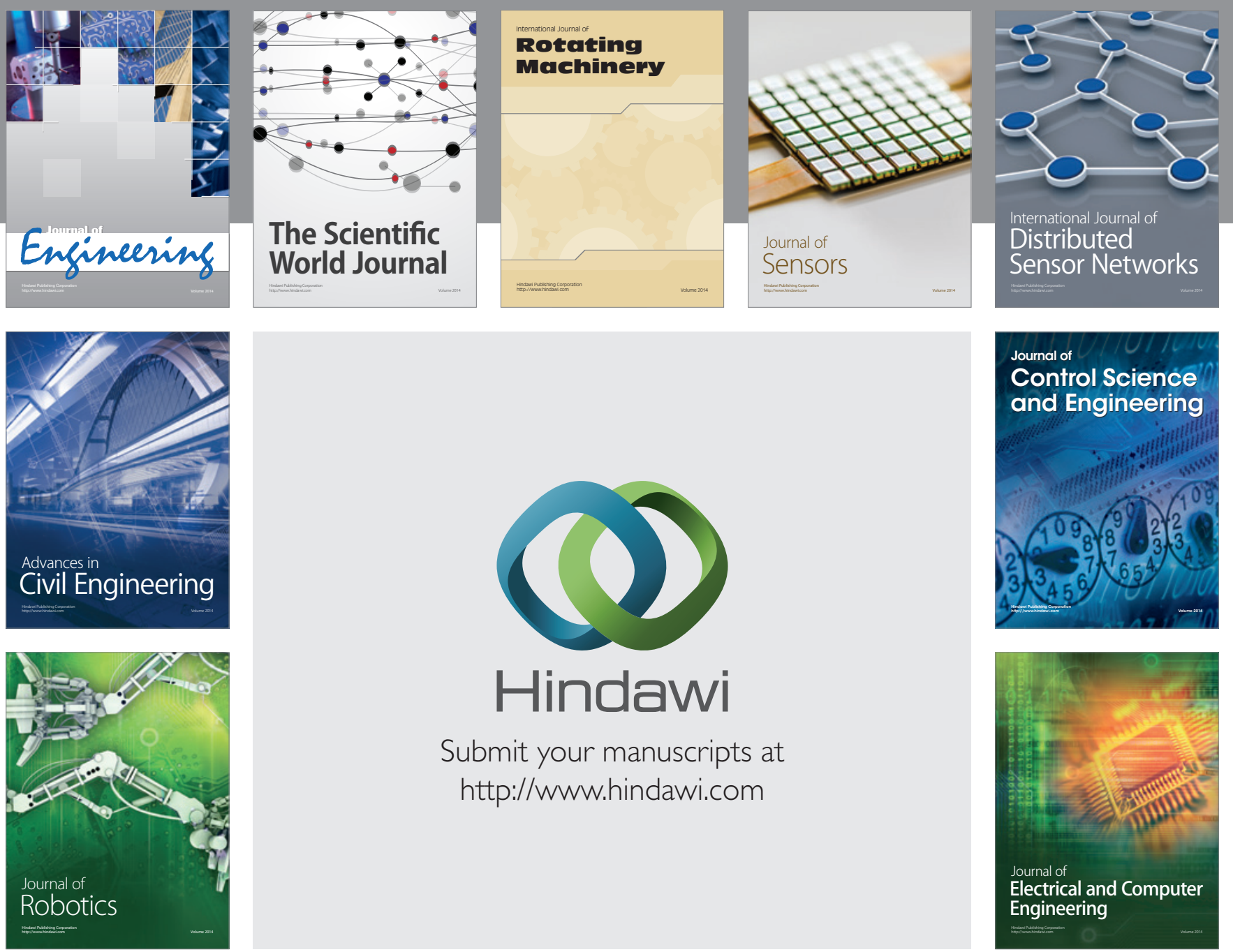

Submit your manuscripts at

http://www.hindawi.com
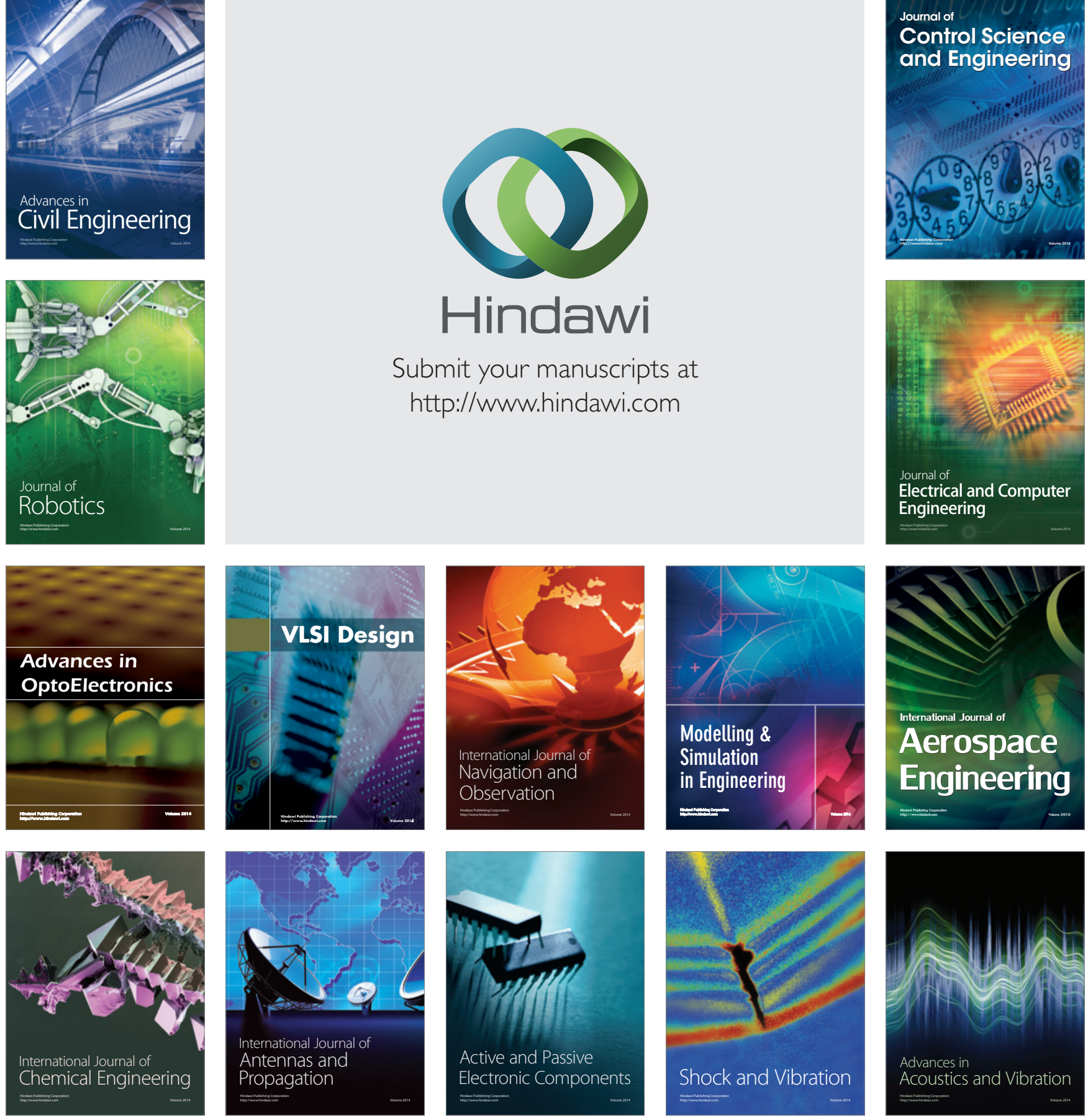